\title{
Textbook of Global Mental Health: Trauma and Recovery. A Companion Guide for Field and Clinical Care of Traumatized People Worldwide. (2012) Richard F. Mollica (Ed.). Harvard Program in Refugee Trauma, Cambridge, 559 páginas.
}

Ángela Ordóñez Carabaño

Universidad Pontificia de Comillas, España

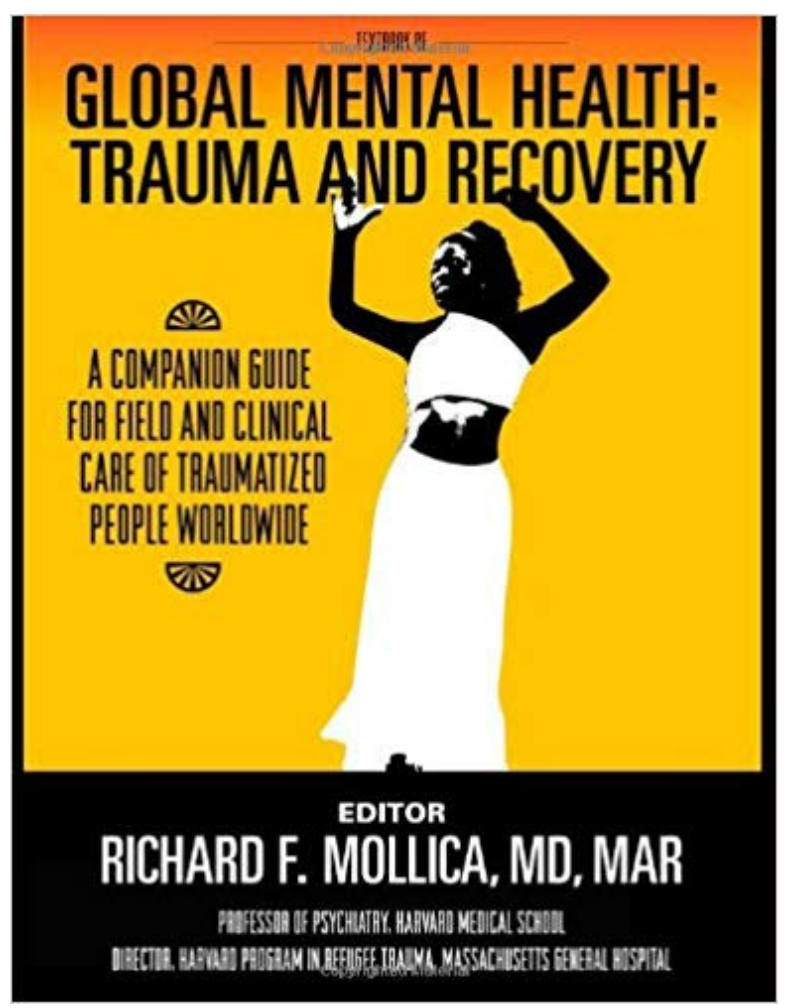

El autor de este primer Manual sobre la Salud Mental Global es, Richard Mollica, profesor de psiquiatría de la Facultad de Medicina de la Universidad de Harvard y director del programa fundado en 1981 para la investigación y docencia sobre experiencias de trauma extremo de población refugiada, creado en un momento de la historia de EEUU en que se creía que poco se podía hacer por este tipo de poblaciones, dada la magnitud y gravedad de las experiencias que habían vivido. En la actualidad este programa (HPRT - Harvard Program in Refugee Trauma) es un referente mundial para todos aquellos que trabajan para sanar las heridas físicas, psicológicas y espirituales de las víctimas de violencia extrema. El Manual que edita Mollica es el fruto su experiencia y de la sensibilidad adquirida tras más de 30 años atendiendo a todo tipo de víctimas a lo largo del mundo.

El HPRT, con Mollica a la cabeza, lideró en 2004 un Congreso Internacional en Roma, titulado "Proyecto Mil Millones” (en alusión al número de personas afectadas por la violencia en todo el mundo), en el que se convocó a los Ministros de Salud de los principales países en situación de postconflicto en aquel momento, con el objetivo de trazar las líneas de acción prioritarias en materia de salud, física y psicológica, para la recuperación de las víctimas. A este encuentro sin precedentes asistieron Ministros de Salud de 35 países en situación de postconflicto (Afganistán, Camboya, El Salvador, Líbano, Perú, Ruanda y Sierra Leona, entre otros), junto con representantes del Banco Mundial, y de las organizaciones de Naciones Unidas más relevantes en materia de salud (OMS y UNICEF). Estos altos cargos se movilizaron por primera vez en la

(cc) EY-NC-ND Este es un artículo Open Access bajo la licencia CC BY-NC-ND. 
historia al reconocer las consecuencias para la salud mental que estaba teniendo la violencia a la que habían sido sometidas miles de personas en sus respectivos países de origen (abuso sexual como arma de guerra, niños soldado, desplazados forzosos, duelo crónico por la desaparición de seres queridos, prisioneros de guerra...). Como fruto de este encuentro se elaboró el primer Plan de Acción para la Salud Mental Global (SMG), recogido en las primeras páginas de este libro, en el que uno de los objetivos era la creación de este Manual que abordara el sufrimiento de las víctimas desde el punto de vista del individuo, de su comunidad y de aquellos que brindan su ayuda en la atención directa. Así nacen estas páginas, producto de la reflexión y la síntesis de algunos de los organismos internacionales implicados en el cuidado y la recuperación de las víctimas, para responder a la necesidad de contar con un texto que pudiera servir de referencia para todos los profesionales que atienden a población víctima de violencia en cualquier lugar del mundo. Se convierte así en el primer libro que trata de abordar de manera holística y sistemática la recuperación de las víctimas de trauma extremo, está organizado en torno a las mismas 8 dimensiones del Plan de Acción para la SMG y fue redactado por expertos en políticas públicas, salud física y psicológica, desarrollo económico, derechos humanos y ayuda humanitaria.

Una de las motivaciones principales de Richard Mollica para la redacción de este libro es la observación sistemática de algunos patrones que se repiten en la respuesta humanitaria con cada catástrofe y cómo estos patrones, pese a la buena intención con que son concebidos, desencadenan con frecuencia un estado que prolonga el sufrimiento de las víctimas durante décadas o incluso durante toda la vida de las comunidades. El autor afirma que esta repetición de patrones disfuncionales se debe a que, desafortunadamente, el mundo de la ayuda humanitaria no siempre incorpora el conocimiento científico obtenido durante décadas de trabajo en terreno con víctimas de trauma y justifica así la necesidad de este libro, que no es otra cosa que una síntesis de los conocimientos ya existentes en este campo tras años de investigación y experiencia directa.

Todavía hoy prevalece en la atención a las víctimas de trauma extremo el tácito mito sobre su resiliencia considerada casi sobrehumana. Llegando a dar por hecho que si sometemos a una persona a la violencia extrema volverá a su estado original una vez que la catástrofe o el conflicto haya terminado. Si bien es cierto que la capacidad para la auto-recuperación de las personas es extraordinaria, esta capacidad necesita un contexto de apoyo considerable desde el punto de vista político, económico y social para poder crecer y desarrollarse. Por desgracia, a la hora de planificar la atención a las víctimas, en numerosas ocasiones, el sistema diseñado es justo el que acaba provocando que empeore la salud psicológica de las personas: generando dependencia económica con la falta de creación de empleo, cronificando situaciones de inferioridad y subordinación por la falta de apoyo económico o de oportunidades educativas..., situaciones que, si fueran abordadas de manera integral, permitirían alcanzar la autosuficiencia necesaria para que las víctimas puedan recuperar la sensación de control sobre sus vidas.

La violencia indiscriminada y los desastres naturales crean un nuevo espacio en la historia de las comunidades. De repente, la agresividad que en el pasado resultaba incomprensible y anecdótica, sin previo aviso, aparece como cotidiana y aceptable. Para las víctimas, acciones que un día consideraron injustas, súbitamente, aparecen justificadas y, con ellas, todo lo fundamental en lo que creían se derrumba. Para aquellos que tratan de sanar las heridas que la violencia deja a su paso, de repente las herramientas que hasta ahora utilizaban en la clínica ya no tienen tanto sentido o incluso obtienen el resultado contrario al que esperaban, como señala Mollica en relación al uso de la empatía que, entendida en numerosos contextos occidentales como "ponerse en los zapatos del otro" puede de hecho, ser experimentada por los supervivientes como un acto de invasión de su espacio personal en un momento de gran vulnerabilidad y tristeza. El autor indica, desde su experiencia de atención a más de 10 mil víctimas de tortura que, de hecho, muy pocos desean que el otro se ponga en sus zapatos. Más aún, esta tendencia puede llegar a abrumar a las víctimas con nuestra compasión, acabar resultando dañina e incluso fomentar la indefensión, la impotencia y la dependencia de la persona que les atiende y de la organización para la que trabaja. A este respecto, el autor propone así aproximarnos al trabajo con víctimas desde un rol en el que ambos se sitúen como seres autónomos e independientes que colaboran juntos para lograr la máxima recuperación posible.

En efecto, los escenarios de violencia extrema suelen despertar un primer impulso cargado de buenas intenciones pero que, en ocasiones, pueden acarrear malos resultados. Así, el autor insiste en que, en estos 
contextos, una mirada holística a la situación de las víctimas se torna más necesaria que nunca, de manera que tanto las personas que trabajan directamente en la recuperación de la salud (y la salud mental), como los trabajadores de la ayuda humanitaria, como los responsables de las políticas que les incumben, deben cooperar y trabajar de la mano para lograr el bienestar y la máxima recuperación. Asimismo, la incapacidad que sienten las víctimas para volver a ser económicamente autosuficientes suele impactar directamente en su bienestar psicológico, y lo mismo ocurre con la pérdida del capital social (las redes de apoyo), de la confianza, de la creencia en un mundo justo (o la expectativa de reciprocidad en la que uno cree que recibirá en la medida en que ha dado) ... Todos estos pilares que sostienen el bienestar de las personas suelen quedar notablemente dañados y su reconstrucción es fundamental para la reducción del odio y el deseo de venganza que, con frecuencia, se deriva de tantas pérdidas consideradas injustas.

Una de las consecuencias típicas de la especialización de los profesionales es que ponemos tanto el foco en lo exclusivo de nuestra tarea que nos desentendemos de los conocimientos y avances en otras áreas, así los economistas se especializan cada vez más en la reconstrucción financiera del país, al margen de lo que esté aconteciendo en los centros educativos, los terapeutas nos especializamos cada vez más en nuevos métodos de tratamiento de estrés postraumático o de la depresión pero, a menudo, vivimos ajenos a los cambios en las políticas que afectan a las víctimas cuyo bienestar procuramos. Mollica insiste en que cuando hablamos de la atención a víctimas de violencia extrema, esta especialización, aunque deseable y necesaria, inevitablemente tiene que ir de la mano de un conocimiento actualizado de lo que están haciendo otros profesionales y que incide de manera directa en las vidas de las personas con las que trabajamos. Con frecuencia aquellos que nos dedicamos a la atención directa en la clínica, desconocemos la situación de la financiación de los programas en los que estamos incluidos o de los problemas para el desarrollo económico de las comunidades en las que las personas a las que atendemos están inmersas, y lo mismo le ocurre a otros profesionales respecto a nuestra práctica clínica (desconocen nuestros objetivos de trabajo, nuestra metodología, el horizonte hacia el que apunta el tratamiento terapéutico). Mollica propone así romper con esta fragmentación de los conocimientos y sugiere leer los capítulos, no como textos estancos e independientes unos de otros, sino como parte de una aproximación integral necesaria para el abordaje del trauma y su recuperación (en un guiño a la obra de Judith Hermann que supuso un punto de inflexión en este campo de estudio). Propone así una definición de salud desde esta mirada holística como "un estado de equilibrio y bienestar personal y social en el que las personas se sienten fuertes, activas, sabias y dignas; en la que sus diversas capacidades y ritmos se consideran valiosos, en la que pueden decidir y elegir expresarse y moverse con libertad".

El autor insiste en la importancia de la definición de salud de la que partamos porque, de ella, se derivará un plan de acción que supere el viejo debate entre las intervenciones denominadas "psicosociales" y la atención más típicamente psiquiátrica. Desde este marco sugiere una aproximación a cada caso con una mirada integradora que él sistematiza en 4 pasos que considera fundamentales para estructurar el análisis, tanto de casos clínicos como de las políticas relacionadas: 1) Descripción del problema; 2) Resultados deseados; 3) Revisión del problema desde las 8 dimensiones descritas en el Plan de Acción para la SMG valorando fortalezas y obstáculos para cada una de ellas; 4) Planificar y llevar a cabo una estrategia para lograr los resultados deseados (paso 2) buscando la transformación de cada una de las 8 dimensiones.

Los capítulos del libro están organizados en torno a estas ocho dimensiones y, para cada una de ellas, nos ofrecen recomendaciones específicas para lograr la recuperación de la salud y el bienestar de las víctimas. Las citadas 8 dimensiones del Plan de Acción son: políticas públicas y legislación sobre salud mental, financiación de la recuperación, servicios de salud mental basados en la investigación, diseño de un programa continuo de psicoeducación en cuestiones relacionadas con la salud mental, coordinación con otras organizaciones que estén trabajando en los mismos objetivos, vincular la atención ofrecida con los derechos humanos fundamentales, garantizar el cumplimiento de las normativas éticas, e investigación y evaluación de la atención ofrecida. Mollica recuerda que los profesionales tendemos a centrarnos únicamente en la dimensión de la que depende más directamente nuestro trabajo en el día a día. Sin embargo, en los casos de violencia generalizada resulta imprescindible que podamos, a la vez, mantener el foco en la persona que tenemos delante, sin perder la perspectiva global de lo que estamos haciendo para poder así garantizar la sostenibilidad de los resultados de nuestra intervención. 
Mollica se sirve de este mismo esquema de 4 pasos y 8 dimensiones para el análisis de la situación de la salud mental desde una perspectiva global de cualquier conflicto bélico (como ocurre en su análisis de la situación de Liberia) y, al mismo tiempo, utiliza este esquema para el análisis del caso clínico concreto de una víctima a la que está atendiendo. Únicamente incluye un matiz cuando se trata de una persona concreta y es que propone estructurar, tanto la evaluación de la situación, como los resultados deseados y el plan de acción, desde las cuatro áreas que considera fundamentales a la hora de entender el bienestar de las personas, o lo que él denomina modelo bio-psico-social-espiritual. Sugiere así, una mirada holística que incluya la perspectiva biológica (que contiene los criterios diagnósticos de psicopatología), psicológica (las dificultades para procesar lo ocurrido, la pérdida de esperanza y motivación y la necesidad de recuperar la sensación de control sobre los acontecimientos), social (asumiendo que la violencia extrema transforma todos los espacios sociales y las relaciones de las personas) y espiritual (como elemento fundamental a la hora de encontrar sentido a lo ocurrido y recuperar una visión positiva del mundo e identificar un nuevo propósito que oriente la vida de las personas).

De cara al tratamiento de víctimas de violencia, el autor propone 7 pasos a seguir basados en su experiencia y en las últimas aportaciones de la investigación: 1. Preguntar a la persona por su historia de violencia (anticiparse sin dar por hecho que acabará contándola), 2. Identificar las consecuencias concretas que la violencia ha tenido en su salud física y psicológica, 3. Establecer un diagnóstico de la situación y planificar el tratamiento, para lo que sugiere dos instrumentos de evaluación de la sintomatología de las víctimas: el HTQ (Harvard Trauma Questionnaire) y el HSCL-25 (Hopkins Symptom Checklist), ambos incluidos en el libro, 4. Derivar, en aquellos casos en que la sintomatología sea muy grave y requiera atención psiquiátrica, 5. Reforzar estrategias de afrontamiento ya presentes en el funcionamiento de la persona (y fomentar aquellas que no esté poniendo en marcha), 6. Sugerir que realicen alguna tarea de manera altruista y actividades que puedan potenciar su dimensión espiritual (mantenerse ocupado, ayudar a otros, meditar o rezar suelen ser muy beneficiosos en estos casos), 7. Reducir conductas de riesgo, 8. Sensibilizarse frente a las diferencias culturales en la expresión y significado atribuido a las emociones, 9. Valorar la necesidad de tratamiento farmacológico complementario, 10. Planificar las siguientes sesiones con él/ella y 11. Anticiparse al desgaste (burnout) típico de la atención a este tipo de poblaciones (supervisando y contrastando nuestra intervención con otros profesionales).

Resultan de especial interés clínico las recomendaciones prácticas que sugiere a partir de la experiencia de la guerra en Líbano y, más concretamente, las sugerencias para la atención de niños y adolescentes en el contexto terapéutico y en las intervenciones en colegios, sobre todo a la hora de establecer el primer contacto para poder generar un contexto seguro y cómodo que permita sentar las bases para el tratamiento posterior.

Terminamos con la cita de Franco Paparo que abre este manual y apunta hacia un modelo de atención a víctimas de violencia extrema cuyo pilar fundamental reside en el potencial sanador que acontece en la propia relación de ayuda y que funciona como eje vertebrador de las propuestas de Richard Mollica: "Puesto que la experiencia central de los pacientes víctimas de trauma es el desempoderamiento y la desconexión, su recuperación debe basarse en devolver cierto poder a la persona y establecer algún tipo de conexión, en primer lugar, con el terapeuta, que tiene que ser capaz de escuchar empáticamente. La curación no puede acontecer mientras la persona permanezca aislada, únicamente puede tener lugar en el contexto de las relaciones". 